ORIGINAL ARTICLE

\title{
LASER VERSUS RADIOTHERAPY IN THE TREATMENT OF EARLY GLOTTIC CARCINOMA
}

\author{
Mohamed Abdel- Azim Mohamed ${ }^{1}$, Alaa Eldden El-Fiky ${ }^{1}$, Abbas Mahmoud Sarhan², Wail Fayez \\ Nasr ${ }^{1}$, Mohamed Ahmed Amin ${ }^{1}$ \\ ${ }^{1}$ Otorhinolaryngology Department, Faculty of Medicine, Zagazig University, Zagazig, Egypt \\ ${ }^{2}$ Radiotherapy Department, Faculty of Medicine, Zagazig University, Zagazig, Egypt
}

Corresponding author:

Mohamed Ahmed Amin

Otorhinolaryngology

Department, Faculty of

Medicine, Zagazig University,

Zagazig, Egypt

mohamedamin7784@gmail.com

$\begin{array}{ll}\text { Submit Date } & 2019-03-14 \\ \text { Revise Date } & 2019-05-04 \\ \text { Accept Date } & 2019-05-06\end{array}$

\section{ABSTRACT}

Background: Laryngeal cancer is one of the most common types of head and neck malignancy, although its optimal primary treatment is still a matter of debate. Methods: Typical patients with laryngeal SCC (90\% at least) are males, over 45 years and heavy smokers. Hoarseness, voice changes, dysphagia, odynophagia, neck mass, dyspnea, referred otalgia and aspiration are the symptoms seen in laryngeal carcinoma. Glottic carcinomas are usually diagnosed earlier and hoarseness is the most common typical symptom. Results: All patients had completed the study. After comparison of the result between the 2 treatment groups, transoral laser excision shows better results than radiotherapy. There is significant difference between laser and radiotherapy in post-operative complications regarding granuloma tissue formation, tumor recurrence and web formation. In laser excision of laryngeal carcinoma, $10 \%$ of cases have post-operative granuloma while in radiotherapy, $66.6 \%$ of them have post-operative granuloma, but no cases has tumor recurrence while in radiotherapy, $33.3 \%$ of them have tumor recurrence. In laser excision of laryngeal carcinoma, $10 \%$ of cases have post-operative web formation while in radiotherapy, $22.3 \%$ of them have post-operative web formation. There is statistically significant difference between laser and radiotherapy in post-operative satisfaction about the voice (voice quality). Radiotherapy shows better results than laser in voice satisfaction. Conclusions: As regard the study, transoral laser excision of early glottic carcinoma shows better control rate and decrease recurrence and complications than radiotherapy.

Keywords: Laser; Radiotherapy; Cancer larynx; Glottic

\section{INTRODUCTION}

L aryngeal cancer is one of the most common types of head and neck malignancy, although its optimal primary treatment is still a matter of debate. Typical patients with laryngeal SCC (90\% at least) are males, over 45 years and heavy smokers. Hoarseness, voice changes, dysphagia, odynophagia, neck mass, dyspnea, referred otalgia and aspiration are the symptoms seen in laryngeal carcinoma. Glottic carcinomas are usually diagnosed earlier and hoarseness is the most common typical symptom [1]
The proper treatment of head and neck squamous cell carcinoma is based on appropriate planning of surgical, radiotherapeutic and medical strategies aimed to control the primary tumor as well as cervical nodal metastases. Prevention and early diagnosis of laryngeal carcinoma is the most effective means for maximizing cure rates and preserving function. Glottic carcinoma tends to be detected at an earlier stage than tumors located at other subsites of the head and neck. [2].

Laryngeal cancer has traditionally been treated with radiotherapy with variable results. It was 
further stated that surgical treatment had other advantages, such as a shorter treatment time, lower morbidity and the possibility of subsequently treating another malignancy in the same area rather than radiotherapy [3].

There are two basic goals of conservation laryngeal surgery:

The first goal is to achieve the same local control. The second goal is to maintain deglutition, phonation and respiration which are the physiological functions of the larynx ${ }^{[4]}$.

\section{Hypothesis:}

We hypothese that laser surgery may be more effective in the treatment early glottic carcinoma and decreases the recurrence rate and this study is done to ascertain this hypothesis or neglect it.

\section{Objectives:}

To compare the results of the transoral laser microsurgery and radiotherapy in the treatment of early glottic carcinoma to decrease the recurrence rate.

\section{Study Design}

\section{METHODS}

Written informed consent was obtained from all participants. The work has been carried out in accordance with the code Ethics of the World Medical Association (Declaration of Helsinki) for studies involving humans.

The study protocol was approved by the local ethics committee (IRB, Zagazig university), This prospective, randomized study comprised 38 patients who had presented to the outpatient clinic between July 2015 till June 2018.

Inclusion criteria were :

- $\quad$ Age: between 40 and 70 years old.

- Sex: male or female.

- Early glottic carcinoma (CIS, cT1a, cT1b, T2).

- $\quad$ No palpable neck nodes (N0).

- $\quad$ Adequate access to the glottic region.

- No contraindications to general anesthesia.

- No previous surgical or radiation treatment for other cancers in the head and neck.

Exclusion criteria were :

- $\quad$ Age: above 70 years old. $\bullet$

$\bullet$

$\bullet$

- Previous surgical or radiation treatment

for other cancers in the head and neck.

Pre-surgical evaluation:

All cases underwent pre-operative preparations before operation.

Pre-operative preparations:

I. History

A detailed history was taken with special concern on:

1. History of hoarseness of voice (onset, course and duration)

2. History of stridor.

3. History of dysphagia.

4. History of other associated diseases.

5. Family History.

II. ENT examination

1. Endoscopic evaluation.

2. Stroboscopic examination.

III. Radiological assessment

Computerized tomography (CT scan) neck.

\section{Surgical Procedures:}

According to the techniques adopted for the management of laryngeal cancer, patients were divided into two groups:

1. Group (A) included 20 cases who offered transoral laser excision of laryngeal carcinoma.

2. Group (B) included 18 cases who offered radiotherapy of laryngeal carcinoma.

In this study, we used Diode laser (DIODE LASER 980+/-10 nm, 30W(MAX), model V100 SNGA13 V872, Wuhan Gigaa Optronics Techonology co,ltd) with laser conducted by fiberoptic fibers (BARE LASER FIBER 400 um model DBLF -40). The laser machine was adjusted at $6 \mathrm{~W}$. power continuous mode.

Safety of the patients is very important which is achieved by:

Eye protection

- Goggles with wave length specific to Diode laser for everyone in the room as well as proper draping over the patient's eyes.

Skin protection 
- Patient skin should be protected by double layer of moistened towels, only proximal end of laryngoscope should be unprotected.

- Periodically remoisten.

- Teeth protection w/ telfa, sponges, etc.

- Laser-safe airway ETT (laser tented tube Medtronic U.S.A.).

- Lowest O2\% that maintains patient's oxygenation should be used.

- No N2O.

- Methylene Blue-saline should be used to inflate cuff.

- Smoke/Vapor suction.

- Important to remove smoke/steam from operative field.

- Suction intermittently if on jet vent.

- CO2 laser smoke condensate was thought to be mutagenic.

- Actively suction when target tissue has high viral load (HPV) (Steiner W. 1993).

In our study, 38 cases of glottic cancer were enrolled in this study 28 patients were T1 (20 T1a \& 8 T1b) and 10 patients were T2.

Among these patients, anterior commissure involvement was in 15 cases.

Among these patients, there was subglottic extension in 6 cases extends down to lower border of thyroid cartilage.

\section{Surgical techniques :}

1. Endoscopic assessment:

Endoscopic examination with (KARL STORZ Germany 27005 PA 30) of the larynx to assess the hidden areas which could not be assessed by stroboscopy like ventricle and subglottic area.

1. Tranoral laser surgery:

A. Lateral endoscopic laryngectomy

It was offered to 3 patients only indicated in glottic T2 tumors not involving the ant $3 \mathrm{~mm}$ of vocal cord. In which we removed the tumor with whole glottic and paraglottic space as deep as the inner perichondrium of thyroid cartilage in one block starting from anterior commissure backward to the vocal process of arytenoid ( Figure 1).

B. Frontolateral endoscopic laryngectomy In 9 patients, we offered them frontolateral endoscopic laryngectomy for glottic T2 tumors involving the anterior attachment of one vocal cord, we excised the anterior attachment of other cord as well to clear the anterior compartment in which we started excision from anterior $3 \mathrm{~mm}$ of the anterolateral cord, excision of the anterior commissure area from as high as the insertion of epiglottis, to thyroid cartilage to as low as the lower border of thyroid cartilage anteriorly going laterally to excise it with glottic and paragllotic space deep to thyroid cartilage - inner perichondrium all as one ( Figure 2).

C. Extended frontolateral endoscopic laryngectomy

In 6 patients, we offered them extended frontolateral endoscopic laryngectomy: If the tumor involves the anterior commissure and/or anterior attachment of other cord, we offered extended frontolateral endoscopic laryngectomy, removing the ant $2 / 3$ of other cord, leaving only its posterior one third, to clear the contralateral compartment. In which the excision as before but starts from $3 \mathrm{~mm}$ behind the posterior margin of the contralateral cord to join both the anterior commissure and ipsilateral glottic, paraglottic the same way as before all are in one block.

D. Piecemeal excision technique

It was offered to 2 patients. The excision started with laser cut in the center of the tumor to detect how deep the tumor invaded then we excised the two halves of the tumor as deep as the invasion was detected taking $3 \mathrm{~mm}$ as safety margin all around the tumor ( Figure 3).

2. Radiotherapy technique:

The radiation technique for patients with $\mathrm{T} 1$ glottic lesions is pretty standard, and setup is quite simple. 13 Patients are treated with two 5 $\times 5 \mathrm{~cm}$ opposed lateral fields that cover the glottic larynx with a $1-$ to $2-\mathrm{cm}$ margin. The superior border of the field is placed at the top of the thyroid cartilage, and the inferior border is extended to the bottom of the cricoid. Anteriorly, the field extends 1 to $2 \mathrm{~cm}$ past the skin surface. Posteriorly, it stops at the anterior edge of the cervical vertebral bodies. The fields may be turned slightly to match the pre- 
vertebral line posteriorly and tilted inferiorly by 5 to 10 degrees to avoid the shoulders, especially in patients with short necks. Both cobalt 60 and 6 megavoltage photons can provide adequate coverage of the glottic region. The field for $\mathrm{T} 2$ lesions are generally slightly larger to account for the greater extent of disease and the potential for supra- or subglottic involvement. It was offered in 5 patients. They usually measure $6 \times 6 \mathrm{~cm}$ and encompass at least one tracheal ring below the cricoid, especially when there is subglottic extension (3 patients). Posteriorly, the field covers the anterior one third to one half of the cervical vertebral bodies. Superior border is extended to $2 \mathrm{~cm}$ above the angle of the mandible to cover the upper jugular nodes, particularly when there is clear evidence of supraglottic extension (2 patients). We can bring in the posterior edges of the $\mathrm{T} 1$ field by $1 \mathrm{~cm}$ and of T2 field by $1.5 \mathrm{~cm}$ for the last few fractions to reduce the dose reached to the pharynx ( Figure 4).

\section{RESULTS}

All patients had completed the study. After comparison of the result between the 2 treatment groups, transoral laser excision shows better results than radiotherapy.

Regarding post-operative complications, formation of granulation tissue is present in only $21.1 \%$ of the studied cases, recurrence of tumor occurs in only $15.8 \%$ of the studied patients, formation of laryngeal web occurred in $15.8 \%$ of the studied patients ( Table 1).

There is statistically significant difference between laser and radiotherapy in post-operative complications regarding granuloma tissue formation, tumor recurrence and web formation. In laser excision of laryngeal carcinoma, $10 \%$ of cases have postoperative granuloma while in radiotherapy, $66.6 \%$ of them have post-operative granuloma, but no cases has tumor recurrence while in radiotherapy, $33.3 \%$ of them have tumor recurrence. In laser excision of laryngeal carcinoma, $10 \%$ of cases have post-operative web formation while in radiotherapy, $22.3 \%$ of them have post-operative web formation ( Table 2 ).

There is statistically significant difference between laser and radiotherapy in post-operative satisfaction about the voice (voice quality). In laser excision of laryngeal carcinoma, $75 \%$ of cases have post-operative satisfaction about their voice while in radiotherapy, $88.8 \%$ of them have postoperative satisfaction about their voice ( Table 3 ).

Table 1. Post-operative complications among the studied laryngeal cancer cases $(\mathrm{N}=38)$.

\begin{tabular}{|c|c|c|}
\hline \multirow[t]{2}{*}{ Item } & \multicolumn{2}{|c|}{ Studied cases $(\mathrm{N}=38)$} \\
\hline & No. & $\%$ \\
\hline \multicolumn{3}{|c|}{ Formation of granulation tissue } \\
\hline Absent & 30 & 78.9 \\
\hline Present & $\begin{array}{l}8 \\
(6 \text { with RT } \\
\text { and } 2 \text { with } \\
\text { laser })\end{array}$ & 21.1 \\
\hline \multicolumn{3}{|c|}{ Tumor recurrence } \\
\hline Absent & 32 & 84.2 \\
\hline Present & $\begin{array}{l}6 \\
\text { (With RT) }\end{array}$ & 15.8 \\
\hline \multicolumn{3}{|c|}{ Laryngeal web formation } \\
\hline Absent & 32 & 84.2 \\
\hline Present & $\begin{array}{l}6 \\
\text { (4 with RT and } \\
2 \text { with laser) }\end{array}$ & 15.8 \\
\hline
\end{tabular}


Table 2. Post-operative granuloma, recurrence and web formation in relation to type of treatment among the studied laryngeal cancer cases $(\mathrm{N}=38)$.

\begin{tabular}{|c|c|c|c|c|c|c|}
\hline \multirow[t]{2}{*}{ Item } & \multicolumn{2}{|c|}{$\begin{array}{l}\text { Laser } \\
(\mathrm{N}=20)\end{array}$} & \multicolumn{2}{|c|}{$\begin{array}{l}\text { Radiotherapy } \\
(\mathrm{N}=18)\end{array}$} & \multirow[t]{2}{*}{ Test } & \multirow[t]{2}{*}{ P-value } \\
\hline & No. & $\%$ & No. & $\%$ & & \\
\hline \multicolumn{7}{|c|}{ Granulation } \\
\hline Absent & 18 & 90 & 12 & 66.6 & \multirow{2}{*}{$\begin{array}{l}\text { Fisher's } \\
\text { Exact }\end{array}$} & \multirow{2}{*}{$\begin{array}{l}0.257 \\
(\mathrm{~S})\end{array}$} \\
\hline Present & 2 & 10 & 6 & 33.3 & & \\
\hline \multicolumn{7}{|c|}{ ecurrence } \\
\hline Absent & 20 & 100.0 & 12 & 66.6 & \multirow{2}{*}{$\begin{array}{l}\text { Fisher's } \\
\text { exact }\end{array}$} & \multirow{2}{*}{$\begin{array}{l}0.257 \\
(\mathrm{~S})\end{array}$} \\
\hline Present & 0 & 0.0 & 6 & 33.3 & & \\
\hline \multicolumn{7}{|c|}{ aryngeal web formation without airway affection } \\
\hline Absent & 18 & 90 & 14 & 77.7 & \multirow{2}{*}{$\begin{array}{l}\text { Fisher's } \\
\text { Exact }\end{array}$} & \multirow{2}{*}{$\begin{array}{l}0.148 \\
(\mathrm{~S})\end{array}$} \\
\hline Present & 2 & 10 & 4 & 22.3 & & \\
\hline
\end{tabular}

Table 3. Post-operative satisfaction about the voice in relation to type of operation among the studied laryngeal cancer cases $(\mathrm{N}=38)$.

\begin{tabular}{|c|c|c|c|c|c|c|}
\hline \multirow[t]{2}{*}{ Item } & \multicolumn{2}{|c|}{$\begin{array}{l}\text { Laser } \\
(\mathrm{N}=20)\end{array}$} & \multicolumn{2}{|c|}{$\begin{array}{l}\text { Radiotherapy } \\
(\mathrm{N}=18)\end{array}$} & \multirow[t]{2}{*}{ Test } & \multirow[t]{2}{*}{ P-value } \\
\hline & No. & $\%$ & No. & $\%$ & & \\
\hline \multicolumn{7}{|l|}{$\begin{array}{l}\text { Voice satisfaction (voice } \\
\text { quality) }\end{array}$} \\
\hline Absent & 2 & 10 & 5 & 27.8 & \multirow{2}{*}{$\begin{array}{l}\text { Fisher's } \\
\text { Exact }\end{array}$} & \multirow{2}{*}{$\begin{array}{l}0.257 \\
(\mathrm{~S})\end{array}$} \\
\hline Present & 18 & 90 & 13 & 72.2 & & \\
\hline
\end{tabular}
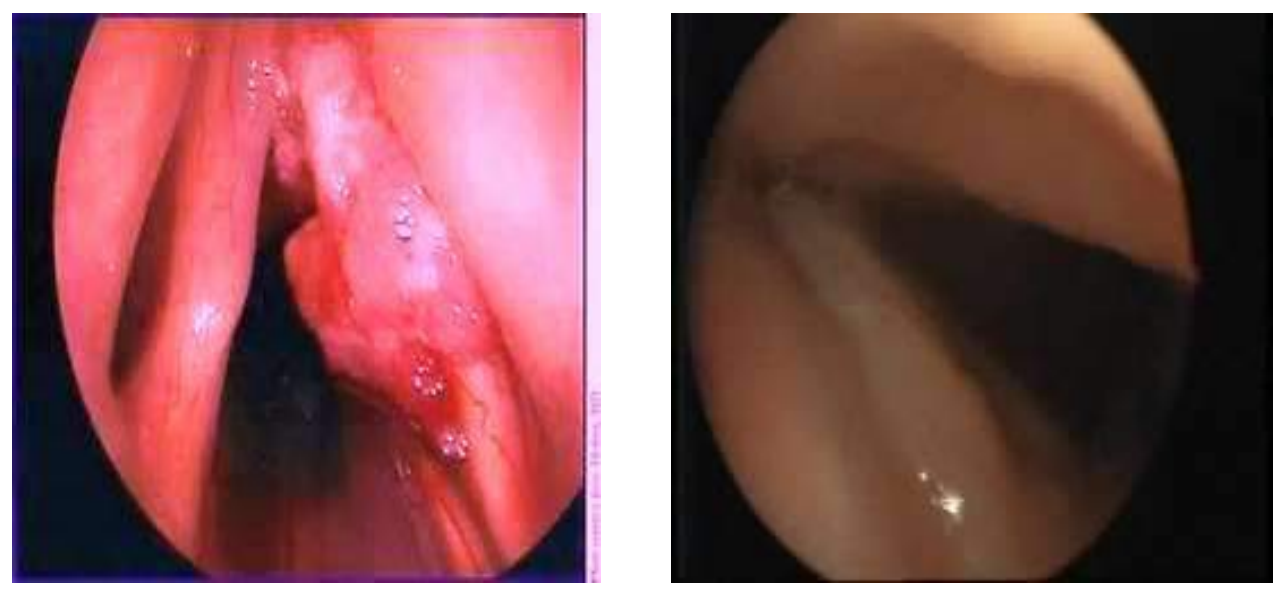

Fig. 1. pre and postoperative view after lateral endoscopic laryngectomy. 

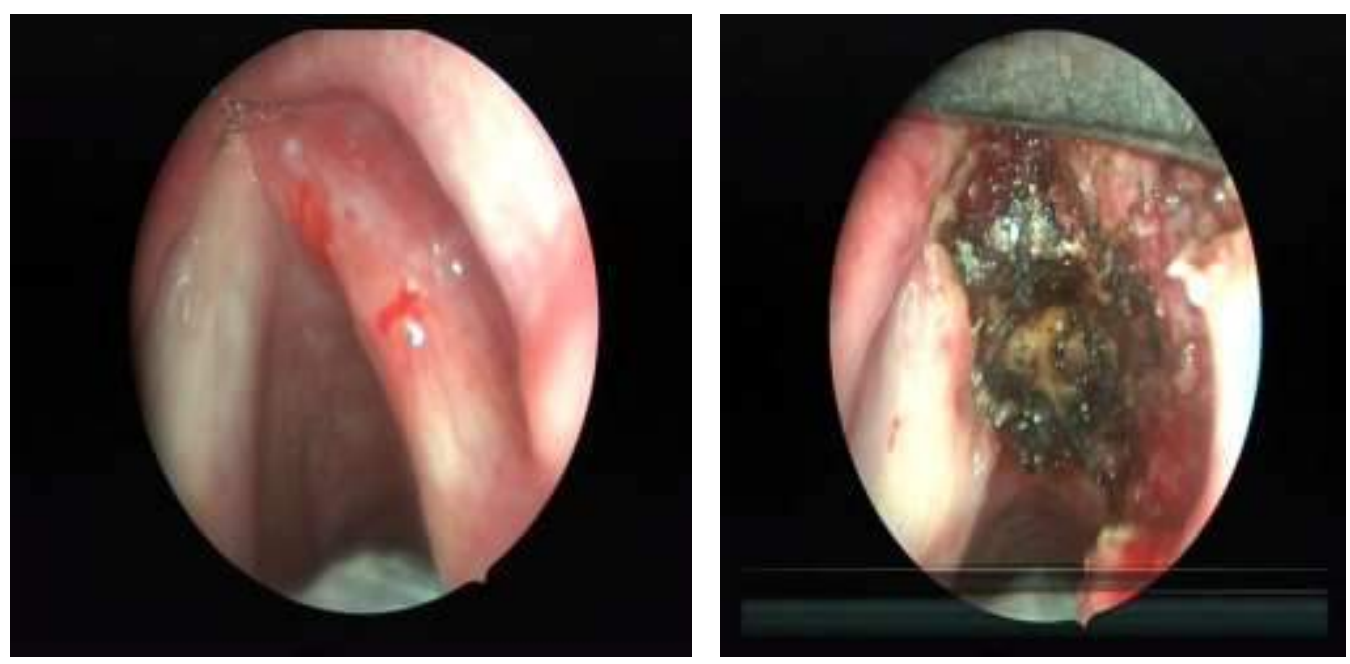

A B

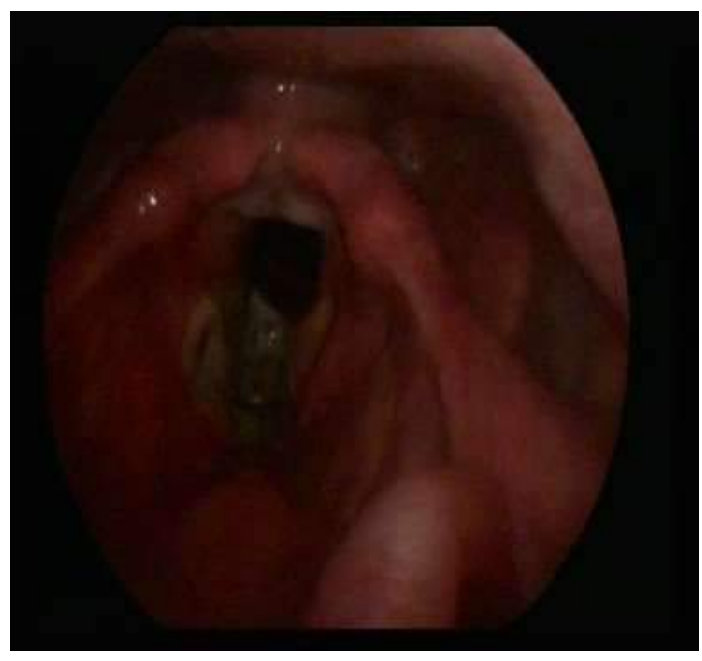

$\mathbf{C}$

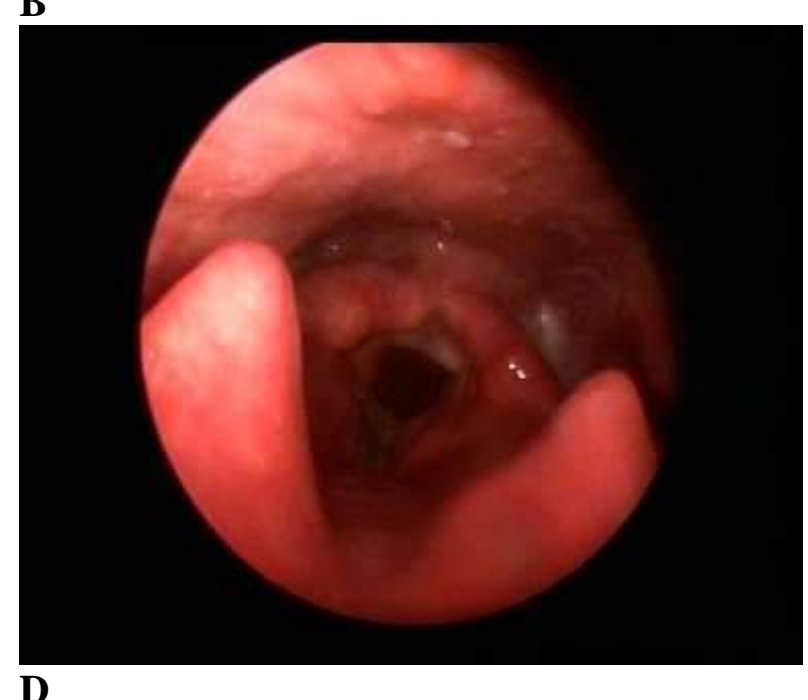

Fig. 2. (A) Pre-operative assessment (B) laser excision (C) early postoperative examination (D) 3 months postoperative view after frontolateral endoscopic laryngectomy 


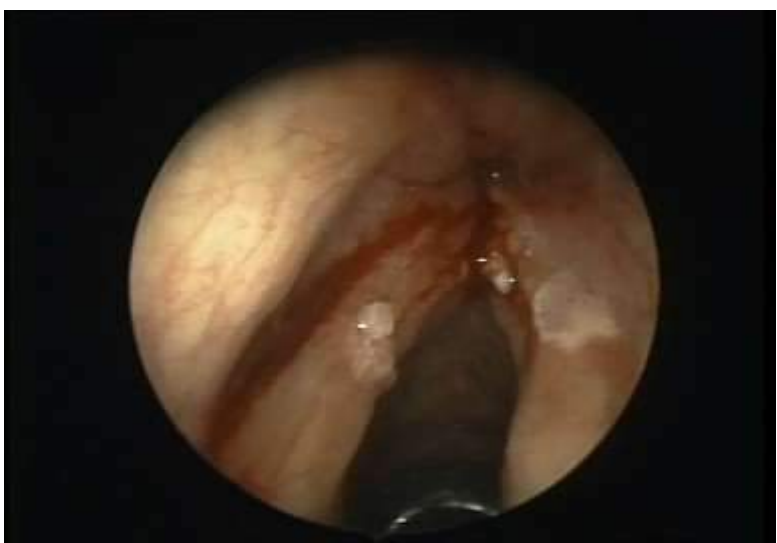

A

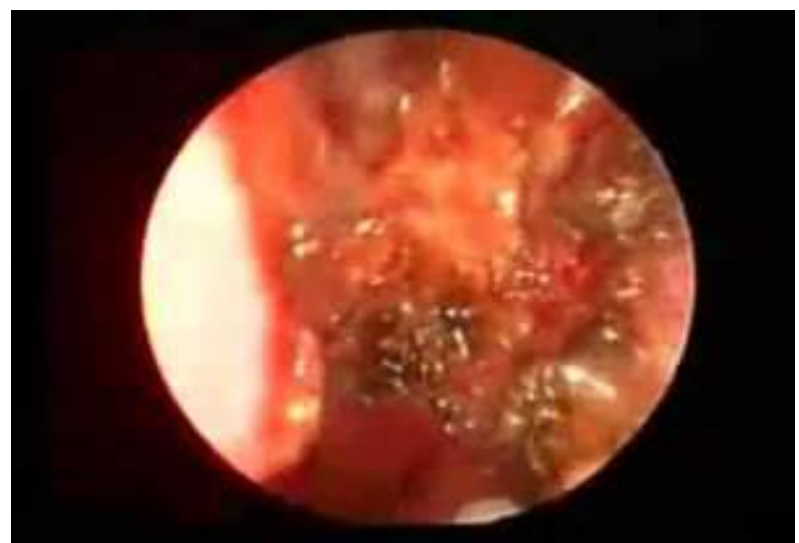

B

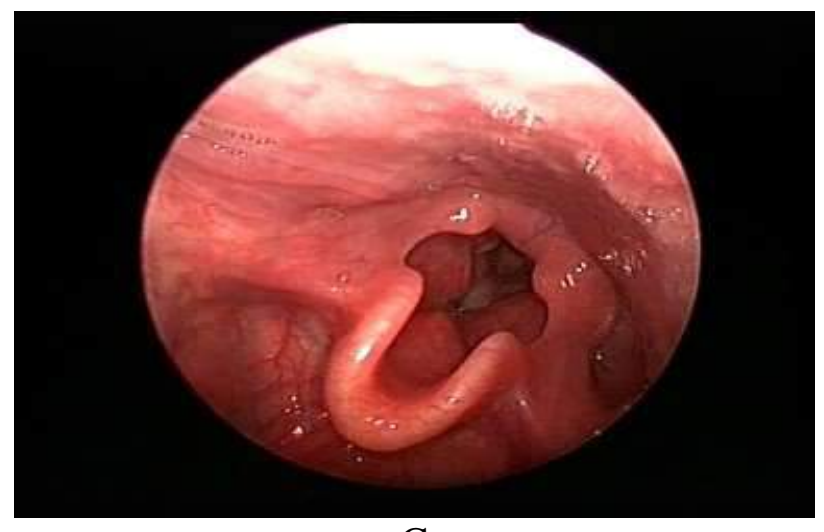

C

Fig. 3. (A) Pre-operative assessment (B) laser excision (C) 3 months postoperative view after endoscopic piecemeal excision technique

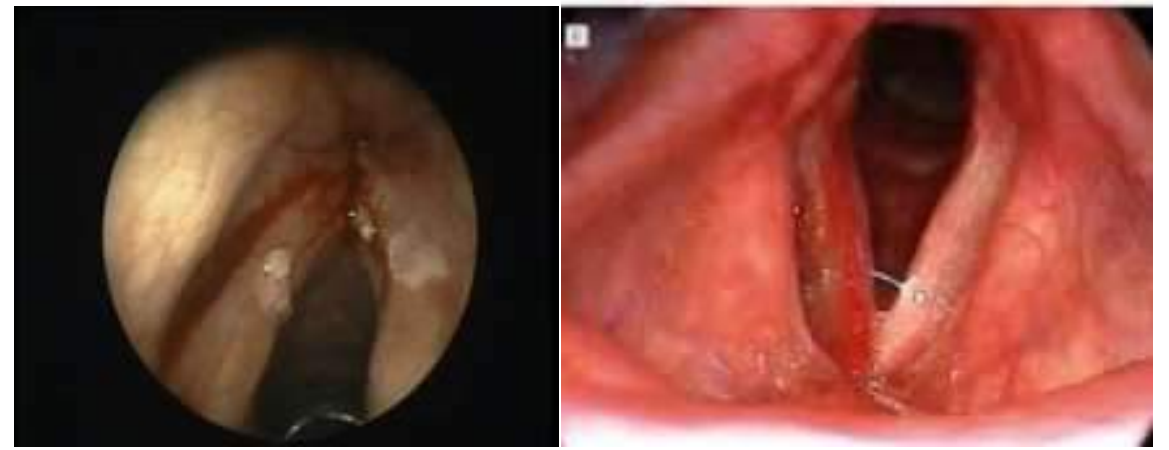

Fig. 4. Pre and 3 months Post radiotherapy follow up

\section{DISCUSSION}

38 cases of glottic cancer enrolled in this study: 28 patients were T1 (20 T1a \& 8 T1b) and 10 patients were T2. These 38 cases were divided to group (A) included 20 cases (11 cases were T1a, 4 cases were T1b, 5 cases were T2) who offered laser excision of laryngeal cancer.
Group (B) included 18 cases ( 9 cases were T1a, 4 cases were T1b, 5 cases were T2) who offered radiotherapy as a line of treatment for early glottic cancer. Laser cases were done under general anesthesia with endotracheal intubation (laser tented tube Medtronic U.S.A) and self 
designed stainless shield to protect the tube when working near by it.

All cases were done using Diode transmitted laser by $4 \mathrm{~mm}$ fibroptic fiber, the machine was adjusted to 6 watts power and continuous mode. No airway fire, no significant hemorrhage, no stridor nor aspiration happened in our study. Oral feeding started 4 hours postoperative. All patients discharged next day.

Patients followed up weekly in 1st month, then monthly in 1 st year, then every 6 months the following years (6m-3yrs).

The radiation technique is delivered for 13 Patients of T1 carcinoma and 5 patients of T2 carcinoma. The course of radiotherapy was about 6 weeks.

In our study, none of our cases needed tracheotomy. Moreau and Pierre used laser to treat invasive or in situ laryngeal carcinoma in 160 patients, doing no tracheotomy postoperatively. This agrees with our series.

The results of this study regarding control rate of T1a (11 cases), T1b (4 cases) tumor in laser was $100 \%$ in 3 years follow up. These results were comparable to (Preuss et al 2008), with T1 tumors, a 5-year follow-up period, had a local control rate ranging from 94.6 to $98.2 \%$ and a rate of laryngeal preservation between 95.5 and $100 \%$. This is comparable to our study, in our series; the local control rate of T1 tumors was $100 \%$ in 3 years and laryngeal preservation $100 \%$.

Anterior commissure involvement in laryngeal carcinoma was reported to be associated with increased local recurrence (Steiner 2013), but the role of anterior commissure in the spread of laryngeal carcinoma (a barrier or path for cancer) is controversial (Moreau 2000 and Pearson 2003). In this study, 15 cases with anterior commissure involvement $(0$ T1a, 5 $\mathrm{T} 1 \mathrm{~b}, 10 \mathrm{~T} 2)$ were enrolled in this study, we achieved local control in them in 9 patients out $15(60 \%)$ control rate for 3 years. 7 patients had been treated with laser and 2 had been treated with radiotherapy. The 6 cases of recurrence were managed by radiotherapy technique ( 2 cases of $\mathrm{T} 1 \mathrm{~b}$ and 4 cases of T2). This was contradictory to Steiner 2013 who considered anterior commissure involvement was clear contraindication to endoscopic laser cancer excision. The only side effect of anterior commissure involvement was postoperative anterior web formation [4]. Fortunately, no patient complained of airway obstruction or stridor throughout the follow up period. Moureu in the year 2000, in a trial to avoid postoperative web formation in $\mathrm{T} 1 \mathrm{~b}$ cases, suggested 2 stage surgery removing one cord in the first stage, then removing the other cord in the second stage two months later. But we were reluctant to use this 2 stage excision, as it involved cutting through the tumor which in our belief it is not oncologic, and this web never affected the air way or interfered with postoperative physiologic speech[5].

Also in this study, there were 10 cases of T2 glottic carcinoma, we achieved local control in 6 cases $(60 \%)$ during 3 years follow up, 5 cases were offered laser excision and 5 cases were offered radiotherapy, while the 4 recurrent T2 cases were treated by radiotherapy.

Comparing our T2 results with that of Steiner 2013, who achieved 60\% control rate in T2 glottic carcinoma in his series and even some of his cases were subjected to re-excision up to 3 sessions [6]. This discrepancy in results can be explained by the fact that, Steiner adopted the piecemeal technique excision which is not oncologic. Cutting through the middle of cancer to see the depth of invasion, has never been oncologically sound as it might lead to seeding of the malignant cells in the surgical field and rendering tumor excision more difficult with high possibility of leaving residual tumor cell behind. While in our T2 5 cases achieved local control in this study $(100 \%)$ were offered enblock excision which is more oncologically proper. [7]. We excised all the laryngeal tissue deep down to the inner perichondrium of the thyroid cartilage and on the surface we left a safety margin $3 \mathrm{~mm}$ all around. This technique offered minimal chance for malignant cells seeding or leaving residual tumor with good success rate. Local control and laryngeal preservation after laser endoscopic 
microsurgery are regarded as excellent by many authors [6].

We limited the indications of laser endoscopic surgery to cancers of the larynx classified as T1 and $\mathrm{T} 2$ which did not have enough time and inertia to invade thyroid cartilage at anterior commissure [8].

Radiotherapy is used to be the standard treatment for limitted glottic $\mathrm{T} 1$ and $\mathrm{T} 2$ carcinoma when voice quality must be preserved [9]. The recurrence rate after glottic carcinoma irradiation is high especially in T2. Recurrence rate is higher when there is subglottic extension or anterior commissure involvement [10].

According to Smith et al, there is no significant difference between external conservative surgery or laser surgery and radiotherapy as regards the local control and the survival rate [11]. However, for Brasnu, the advantage of the laser endoscopic surgery is to avoid incision of skin and platysma, minimal hospital stay, to avoid surgical complications of fistula, tracheostomy, aspiration, pulmonary infection to keep swallowing and speech functions and to avoid the side effects of radiotherapy. This by far agrees with our study [12].

In the series of Smith et al [11], as in our study, postoperative voice quality depended on the type of cordectomy. The voice quality was worse if cordectomy was extended (bilateral type III, type Va, and type Vc). By comparing the quality and voice recovery time after laser endoscopy and after radiotherapy, Brasnu et al concluded that voice quality was normal 3 months after laser cordectomy [12].

\section{CONCLUSION}

Laser and radiotherapy are alternative methods for treatment of early glottic carcinoma. Radiotherapy shows better results as regards voice satisfaction but as regards tumor recurrence and granuloma formation, laser shows better results.

\section{Declaration of interest}

The authors report no conflicts of interest. The authors alone are responsible for the content and writing of the paper.

\section{Funding information:None declared} REFERENCES

1- Jemal A, Murray T, Ward E, Samuels A, et al Cancer Statistics, CA Cancer J Clin ; (2005): 55:10-30.

2- Brendbo K, Benninger MSLaser resection ofTj, glottic carcinomas: results and postoperative voice quality. Acta Otolaryngol; (2004): 124: 976-979.

3- Bosetti C, Garavello W and Gallus S. Effects of smoking cessation on the risk of laryngeal cancer: an overview of published studies: Oral Oncol (2006): 42(9): 866-72.

4- Karasalihoglu AR, Yagiz R, Tas A, Uzun C, Adali MK and Koten M. Supracricoid partial laryngectomy with cricohyoidopexy and cricohyoidoepiglottopexy: functional and oncological results. J Laryngol Otol; (2004): 118(9): 671-675.

5- Moreau. Laryngoscope, (2000): 110(6).1000-1006.

6- Lester SW et al 'How does that sound?': objective and subjective voice outcomes following $\mathrm{CO} 2$ laser resection for early glottic cancer. J Laryngology \&Otology. (2011): 125:1251-1555.

7- Peretti G, Piazza C, Cocco D, De Benedetto L, Del Bon F, Redaelli De Zinis LO, et al Transoral CO(2) laser treatment for T(is)-T(3) glottic cancer: the University of Brescia experience on 595 patients. Head Neck; ( 2010): 32(8):977-83.

8- Foote RL, Olsen KD and Buskirk SJ. Laryngectomy alone for T3 glottic cancer. Head Neck; (1994): 16: 406-412.

9- Shah JP. Patterns of cervical lymph node metastasis from squamous carcinomas of the upper aerodigestive tract. Am J Surg; (1990): 160: 405-9.

10- Bron LP, Soldati D. and Zouhair A. Treatment of early stage squamous-cell carcinoma of the glottic larynx: endoscopic surgeryor cricohyoidoepiglottopexy versus radiotherapy. Head Neck; (2001): 23: 823-829.

11- Smith JC, Johnson JT, CognettiDM, Landsittel DP, GoodingWE, Cano ER, et alQuality of life, functional outcome, and costs of early glottic cancer. Laryngoscope; (2003): 113(1):68-76.

12- Brasnu D LO, Hans O, Menrad M, de Mones E Behm E, and La chirurgie conservatric des cancers du larynx et du pharynx paris: Amplifon (2005): (12) : 681-6.

To Cite This Article: Mohamed AA, Alaa EE, Abbas MS, Wail FN, Mohamed AA*. Laser versus radiotherapy in the treatment of early glottic carcinoma.ZUMJ 2019;25(6);941-949.DOi: 10.21608/zumj.2019.10518.11060. 